\title{
Oxygen Tension Modulates Neurite Outgrowth in PC12 Cells Through A Mechanism Involving HIF and VEGF
}

\author{
Damian C. Genetos • Whitney K. Cheung • \\ Martin L. Decaris • J. Kent Leach
}

Received: 27 October 2009 / Accepted: 28 December 2009/Published online: 27 January 2010

(C) The Author(s) 2010. This article is published with open access at Springerlink.com

\begin{abstract}
Cell-based approaches are a promising therapeutic strategy for treating injuries to the nervous system, but the optimal means to promote neurite extension and direct cellular behavior are unclear. Previous studies have examined the behavior of neural-like cells in ambient air $(21 \%$ oxygen tension), yet these conditions are not representative of the physiological oxygen microenvironment of neural tissues. We hypothesized that neuronal differentiation of a model neural cell line (PC12) could be controlled by modulating local oxygen tension. Compared to ambient conditions, PC12 cells cultured in reduced oxygen exhibited significant increases in neurite extension and total neurite length, with $4 \%$ oxygen yielding the highest levels of both indicators. We confirmed neurite extension was mediated through oxygen-responsive mechanisms using small molecules that promote or inhibit HIF- $1 \alpha$ stabilization. The hypoxic target gene $V e g f$ was implicated as a neurotrophic factor, as neurite formation at $21 \%$ oxygen was mimicked with exogenous VEGF, and a VEGF-neutralizing antibody attenuated neurite formation under reduced oxygen conditions. These findings demonstrate that behavior of neural-like cells is driven by the oxygen microenvironment via VEGF function, and suggest
\end{abstract}

Damian C. Genetos and Whitney K. Cheung contributed equally to this work.

D. C. Genetos

Department of Surgical and Radiological Sciences,

School of Veterinary Medicine, University of California,

Davis, CA, USA

W. K. Cheung $\cdot$ M. L. Decaris $\cdot$ J. K. Leach $(\square)$

Department of Biomedical Engineering, College of Engineering,

University of California, Davis,

451 Health Sciences Drive,

Davis, CA 95616, USA

e-mail: jkleach@ucdavis.edu promising approaches for future applications in neural repair.

Keywords Oxygen tension · Neurite extension · PC12 .

Hypoxia-inducible factor . Vascular endothelial growth factor

\section{Introduction}

Current approaches to restore mobility and control following traumatic nerve injury or the loss of mitotically inhibited neurons are constrained to limited surgical intervention techniques and vigorous physical therapy (Hurlbert 2006). Cell-based approaches to neural repair, in which cells that may directly participate in healing are transplanted into the defect site, are a promising therapeutic strategy and may provide a potential treatment alternative. A host of cells have been examined for their capacity to promote or directly participate in neural repair including neurons from donor tissues, glial cells, adult-derived stromal cells from the bone marrow and adipose compartments, and neurons differentiated from embryonic stem cells (Schmidt and Leach 2003; Safford and Rice 2005). While examination of their behavior in vitro has expanded our understanding of how these cells contribute to neural repair, these approaches have failed to translate to viable neural reparative therapies to date.

The majority of tissue culture is performed in ambient oxygen $(21 \%)$, yet physiological oxygen tensions range from nearly $0 \%$ in cartilage to $3-4 \%$ in human brain tissue and up to $14 \%$ in alveolar blood (Chen et al. 2007). Ambient oxygen levels may induce apoptosis through exposure to reactive oxygen species or alter cellular phenotype over time (Milosevic et al. 2005). Numerous cell types including hepatocytes, bone marrow stromal 
cells, and cells of the neuronal phenotype exhibit profound differences from their native behavior when placed in respective physiological oxygen microenvironments (Chen et al. 2001; Zhu et al. 2005; Potier et al. 2008). For example, oxygen tension differentially regulates long-term expansion and apoptosis for neural precursor cells in vitro depending on their stage of commitment (Chen et al. 2007). Studies have also concluded that reduced or ischemic oxygen conditions can promote survival, proliferation, and differentiation of cells of the neuronal lineage (Milosevic et al. 2005; Burgers et al. 2008; Horie et al. 2008). In light of the critical importance of the oxygen microenvironment on cellular behavior, we hypothesized that the culture of a model neuronal cell line (rat pheochromocytoma PC12 cells) at physiologically relevant oxygen tensions would promote neuronal differentiation. We observed that reductions in oxygen tension from $21 \%$ increased neurite formation and total neurite length, both of which occurred maximally under physiologically relevant oxygen tensions.

\section{Materials and Methods}

\section{PC12 Maintenance}

PC12 cells (CRL-1721, ATCC) were cultured in complete media: Ham's modification of Kaighn's medium containing L-glutamine (Sigma Aldrich) with $15 \%$ horse serum (ATCC), 2.5\% fetal bovine serum (JR Scientific), $1 \%$ penicillin/streptomycin (Mediatech), and $1.5 \mathrm{~g} / \mathrm{L}$ sodium bicarbonate. Cells were seeded in tissue culture flasks at $2 \times$ $10^{4}$ cells $/ \mathrm{cm}^{2}$ and maintained in a standard incubator $\left(37^{\circ} \mathrm{C}\right.$, $5 \% \mathrm{CO}_{2}$ ). Media was changed every 3 days, and cells were subcultured $1: 2$ biweekly with $0.25 \%$ trypsin/EDTA.

\section{PC12 Response to the Oxygen Microenvironment}

PC12 cells were cultured upon a collagen substrate. Collagen I solution $(0.5 \mathrm{mg} / \mathrm{mL}$, BD Biosciences $)$ was prepared in $0.02 \mathrm{~N}$ acetic acid, and $100 \mu \mathrm{L}$ was pipetted into 12-well plates and allowed to incubate at room temperature for $1 \mathrm{~h}$ before aspiration, after which time wells were washed three times with 10× PBS and allowed to air dry in sterile conditions. Substrates were rehydrated in PBS for $10 \mathrm{~min}$, gently aspirated, and cells were seeded at $2 \times 10^{4}$ cells $/ \mathrm{cm}^{2}$ in complete media and placed in a standard $\mathrm{CO}_{2}$ incubator for $24 \mathrm{~h}$. Media was then aspirated and replaced with fresh media, and plates were placed inside hypoxia chambers (Billups-Rothenberg) and pumped down with a mixture of nitrogen and carbon dioxide to the desired oxygen tension. Ambient oxygen (21\%) served as the control. Oxygen content was measured using an oxygen sensor attached to the chamber outflow (Billups-Rothenberg).
Inflow and outflows were sealed and chambers were placed in a $37^{\circ} \mathrm{C}$ incubator for $72 \mathrm{~h}$. The metabolic activity of PC12s cultured in different oxygen conditions was measured in the final $4 \mathrm{~h}$ prior to cellular characterization using an alamarBlue assay (Serotec) following the manufacturer's instructions (Hamid et al. 2004). Changes in cell morphology and frequency of neurite extension were measured as described below.

To validate the role of the oxygen microenvironment, cells were cultured in complete media supplemented with either YC-1 (100 $\mu \mathrm{M}$, Cayman Chemical) or $\mathrm{CoCl}_{2}$ (100 $\mu \mathrm{M}$, Sigma Aldrich) (Yeh et al. 2007; Sun et al. 2007). We examined the potential contribution of VEGF activity on neurite projection by culturing $\mathrm{PC} 12 \mathrm{~s}$ in the presence of recombinant rat $\mathrm{VEGF}_{165}(50 \mathrm{ng} / \mathrm{mL})$, while endogenous VEGF activity was neutralized by the addition of anti-rat $\mathrm{VEGF}_{165}(500 \mathrm{ng} / \mathrm{mL}$; both from Peprotech).

\section{Neurite Quantification}

After $72 \mathrm{~h}$ in the experimental oxygen tension and culture conditions, samples were rinsed $1 \times$ with PBS and imaged using a Nikon TE2000U inverted microscope and Spot RT digital camera. Neurites were defined as projections from the cells that deviate from their normal morphology and measure greater than $5 \mu \mathrm{m}$ from the cell body to tip (Leach et al. 2007). Cells were located and individually marked using Adobe Photoshop. Total cell number and cells exhibiting neurites per field of view were recorded. Quantification of neurite length was performed on 100 randomly selected neurite-bearing cells from each oxygen tension by tracing individual neurites using the NeuronJ plugin for ImageJ software (Meijering et al. 2004).

\section{Western Blot Analysis}

After 8 or $72 \mathrm{~h}$, plates were removed from hypoxia chambers, washed with PBS, and total protein was collected in $4 \times$ sample buffer $(20 \%$ glycerol, $4 \%$ SDS, $0.05 \%$ bromophenol blue, $160 \mathrm{mM}$ Tris $-\mathrm{HCl}$, and $200 \mathrm{mM}$ DTT). Protein concentration was determined using the Amido Black method (Sheffield et al. 1987). Twenty to $40 \mu \mathrm{m}$ of protein per sample were resolved in $10 \%$ Tris$\mathrm{HCl}$ acrylamide gels and transferred onto $0.2 \mathrm{~mm}$ nitrocellulose. Blots were blocked in $0.5 \%$ nonfat milk in Tris-buffered saline with $0.05 \%$ Tween-20 (TBST) for $2 \mathrm{~h}$ and probed with anti-rat polyclonal hypoxia-inducible factor- $1 \alpha$ (HIF-1 $\alpha)$ antibody (1:400 in blocking buffer; Cayman Chemical, 10006421) overnight at $4^{\circ} \mathrm{C}$. Membranes were washed, probed with horseradish peroxidase-conjugated secondary antibodies at 1:2,500 and reactive bands were visualized using enhanced chemiluminescence and X-ray film. 
Quantitative PCR Analysis of PC12 Gene Transcription

Total RNA was collected with RNeasy Mini kit (Qiagen) according to manufacturer's instructions and included oncolumn digestion of genomic DNA. RNA quality was assessed by the ratio of absorbance at 260 and $280 \mathrm{~nm}$. Total RNA $(0.2-1 \mu \mathrm{g})$ was reverse-transcribed with Superscript First-Strand Synthesis System (Invitrogen). Quantitative RT-PCR was performed using TaqMan ${ }^{\circledR}$ Universal PCR Master Mix (Applied Biosystems) on a Mastercycler $^{\circledR}$ realplex2 (Eppendorf); proprietary primers and probes, whose sequences are not disclosed, were purchased from Applied Biosystems. Amplification conditions were $50^{\circ} \mathrm{C}$ for $2 \mathrm{~min}, 95^{\circ} \mathrm{C}$ for $10 \mathrm{~min}$, followed by 40 cycles at $95^{\circ} \mathrm{C}$ for $15 \mathrm{~s}$ and $60^{\circ} \mathrm{C}$ for $30 \mathrm{~s}$. Quantitative PCR results were first normalized to ribosomal RNA $18 \mathrm{~S}$ (18S) transcript level to yield $\Delta C_{\mathrm{t}}$. Results are expressed as $2^{-\Delta C \mathrm{t}}$, after Livak and Schmittgen (2001).

\section{Statistical Analysis}

Data were compared using a paired, two-tailed Student's $t$ test or ANOVA. Variability was calculated as standard error and significance was defined as $p<0.05$. Statistical analysis was performed using InStat 3 or Prism (both from GraphPad).
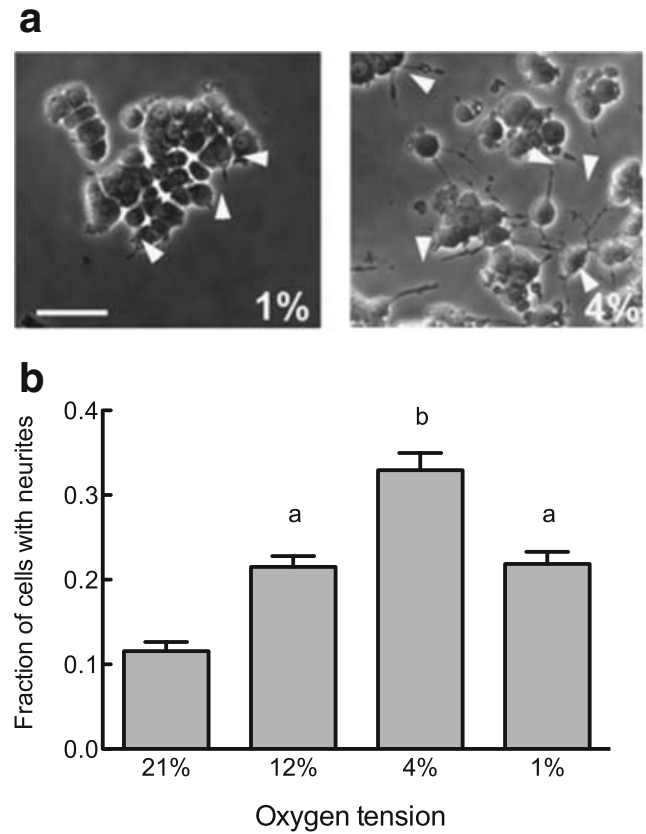

Figure 1 Reductions in local oxygen tension promote neurite formation in PC12 cells. a PC12 cells display differences in neurite extension when cultured at indicated oxygen tensions. Arrowheads indicate neurites; scale bar represents $50 \mu \mathrm{m}$. b Fraction of cells extending neurites under varying oxygen tension. $a$ indicates $p<0.001$ by ANOVA compared to $21 \%$ oxygen; $b$ indicates $p<0.001$ by
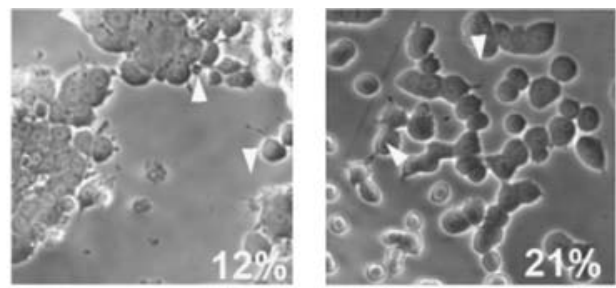

\section{Results}

Reductions in Oxygen Tension Increase Neurite Formation by PC12 Cells

PC12 cells readily adhered to the collagen substrate and possessed sporadic short neurites under typical culture conditions at $21 \%$ oxygen tension (Fig. 1a). We observed the formation of longer and more frequent neurites in cells cultured for $72 \mathrm{~h}$ under reduced oxygen tensions of $1 \%$, $4 \%$, or $12 \%$ (arrowheads, Fig. 1a). The greatest fraction cells extending of neurites occurred in cells cultured at $4 \%$ oxygen $(0.330 \pm 0.020)$, a three-fold increase versus cells maintained at $21 \%$ oxygen $(0.116 \pm 0.011$; Fig. 1b). In addition to increased frequency of neurite projection, cells cultured in reduced oxygen tensions exhibited increases in neurite length, which translated to apparent differences in network maturity and neurite interaction (Fig. 1c). Specifically, PC12 cells cultured in $1 \%, 4 \%$, or $12 \%$ oxygen tension exhibited a two- to fourfold increase in total neurite length compared to those cultured at $21 \%$ oxygen tension $(1,142 \pm 72 \mu \mathrm{m})$, with the greatest aggregate neurite length detected at $4 \% \mathrm{O}_{2}(4,146 \pm$ $449 \mu \mathrm{m})$. Because neurite formation and length was maximal under $4 \%$ oxygen tension, we focused on this culture condition for the remainder of the studies.

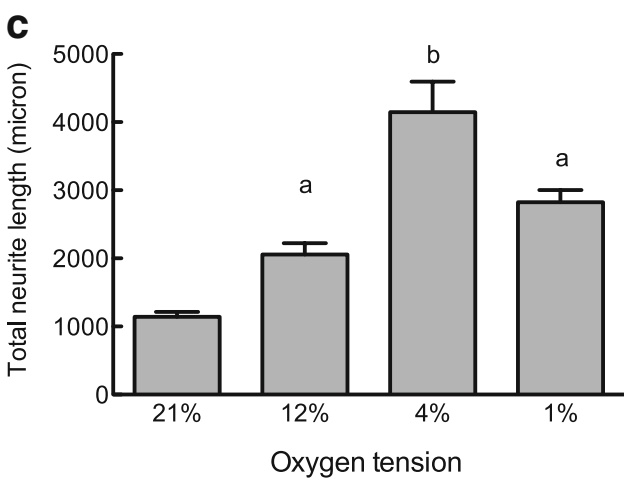

ANOVA compared to $21 \%, 12 \%$, or $1 \%$ oxygen. $n=$ minimum of four per condition. c Quantification of average total neurite length of 100 randomly selected cells in each condition. $a$ indicates $p<0.001$ by ANOVA compared to $21 \%$ oxygen; $b$ indicates $p<0.001$ by ANOVA compared to $21 \%, 12 \%$, or $1 \%$ oxygen. $n=$ minimum of four per condition 


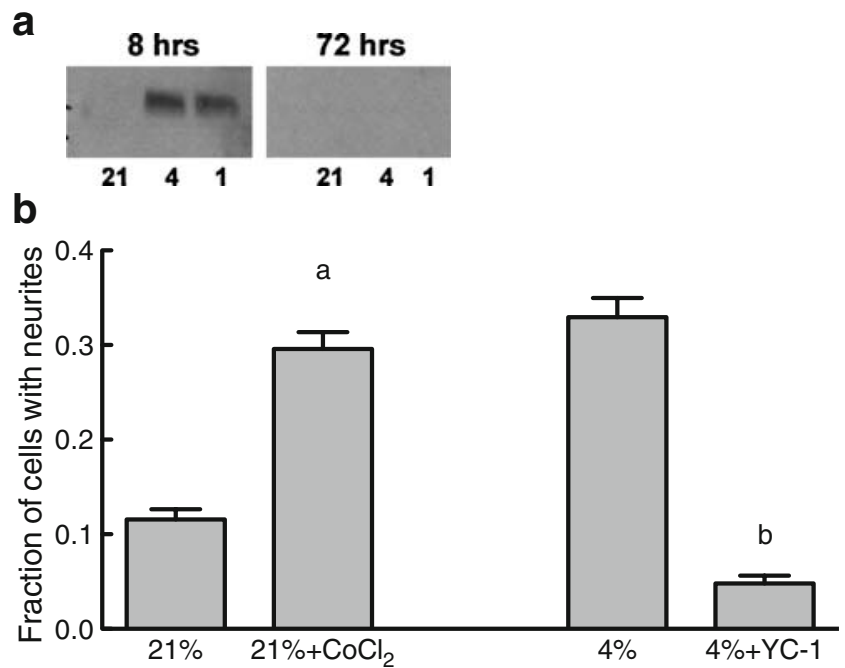

\section{Condition}

Figure 2 Manipulation of HIF signaling mediates neurite formation. a Western blotting for HIF- $1 \alpha$ after $8 \mathrm{~h}$ (left) and $72 \mathrm{~h}$ (right) for PC12 cells cultured in $21 \%, 4 \%$, or $1 \%$ oxygen tension. b The hypoxia mimetic $100 \mu \mathrm{M} \mathrm{CoCl} 2$ increases the frequency of PC12 cells elaborating neurites under $21 \%$ oxygen culture, whereas HIF- $\alpha$ inhibition with $100 \mu \mathrm{M} \mathrm{YC}-1$ abrogated hypoxia-driven neurite formation under $4 \%$ culture. a indicates $p<0.001$ by $t$ test compared to $21 \%$ oxygen; b indicates $p<0.001$ by $t$ test compared to $4 \%$ oxygen. $n=$ minimum of four per condition

\section{HIF and VEGF Signaling Mediate Neurite Formation}

Hypoxia-inducible factors (HIFs) are transcription factors which are stabilized under reduced pericellular oxygen; HIF target genes are implicated in angiogenesis and glycolysis (Semenza 2007a, 2007b). Under normoxic conditions, HIF- $\alpha$ subunits are constitutively ubiquitinated and proteasomally degraded, whereas hypoxia promotes their stabilization via inhibition of the ubiquitin ligase VHL. PC12 cells cultured at $4 \%$ or $1 \%$ oxygen tension responded by stabilizing HIF- $1 \alpha$ levels in samples collected after 8 hours of hypoxic culture, while cells maintained in ambient air did not exhibit any detectable protein by Western blotting; HIF- $1 \alpha$ stabilization was completely abolished after $72 \mathrm{~h}$, suggesting that PC12 response to hypoxia is transient, and cells rapidly adapt to reductions in oxygen tension (Fig. 2a). To examine whether HIF stabilization mediated neurite extension, PC12 cells were cultured in the presence of $\mathrm{CoCl}_{2}$, a hypoxia mimetic, or $\mathrm{YC}-1$, an inhibitor of HIF- $1 \alpha$ translation. Cells cultured at $21 \%$ oxygen in the presence of $100 \mu \mathrm{M}$ $\mathrm{CoCl}_{2}$ demonstrated significantly increased frequency of neurite extension compared to $\mathrm{CoCl}_{2}$-free cultures at $21 \%$ oxygen tension (Fig. 2b). Addition of $100 \mu \mathrm{M} \mathrm{CoCl}_{2}$ to cells cultured at $4 \%$ oxygen revealed no additive effect of reduced oxygen tension upon neurite frequency, suggesting saturation of the neurotrophic response to hypoxia (data not shown). HIF signaling was further implicated in the neurotrophic effect of hypoxia through the HIF antagonist YC-1, which attenuated neurite formation in cells cultured under $4 \%$ oxygen tension (Fig. 2 b). These data demonstrate that HIF- $\alpha$ signaling occurs under hypoxic culture of $\mathrm{PC} 12$ cells and is required for hypoxic-driven neuritogenesis.

Vascular endothelial growth factor (VEGF) is an angiogenic factor released by cells in response to certain stressors, including hypoxia. PC12 cells cultured under $4 \%$ or $1 \%$ oxygen tension demonstrated increased Vegf transcript compared to $21 \% \mathrm{O}_{2}$ control cultures, confirming that Vegf is responsive to hypoxic culture in $\mathrm{PC} 12$ cells (Fig. 3a). We next sought to determine whether the neurotrophic effect of hypoxia occurred via VEGF signaling. Similar to cells treated with the hypoxia mimetic $\mathrm{CoCl}_{2}$, addition of $50 \mathrm{ng} / \mathrm{mL} \mathrm{VEGF}_{165}$ to cells cultured at $21 \% \mathrm{O}_{2}$ dramatically increased the fraction of cells with neurite projections (Fig. $3 b$ ). In contrast, the addition of a VEGF-inhibiting antibody to culture media significantly attenuated neurite projection in cells cultured at $4 \%$ oxygen.

a

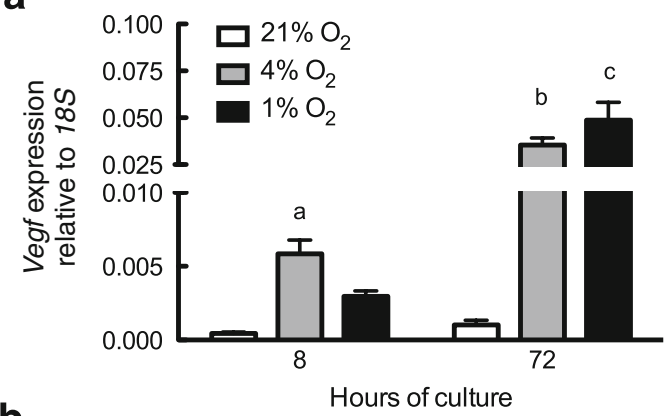

b

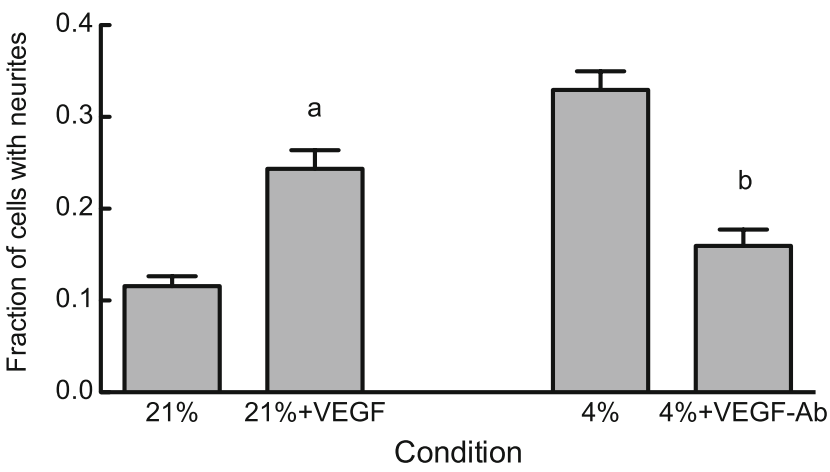

Figure 3 VEGF signaling mediates neurite formation. a Levels of Vegf transcript after culture for 8 or $72 \mathrm{~h}$ under $21 \%, 4 \%$, or $1 \%$ oxygen tension culture. $a$ indicates $p<0.05$ compared to $21 \%$ or $1 \%$ oxygen at $8 \mathrm{~h} ; b$ indicates $p<0.05$ compared to $21 \%$ oxygen at $72 \mathrm{~h} ; c$ indicates $p<0.01$ compared to $21 \%$ oxygen at $72 \mathrm{~h}$. b Addition of exogenous VEGF $(50 \mathrm{ng} / \mathrm{mL})$ increases the frequency of PC12 cells elaborating neurites under culture at $21 \%$ oxygen tension, whereas cells cultured at $4 \%$ oxygen in the presence of a VEGF-neutralizing antibody failed to extend neurites. $a$ indicates $p<0.001$ by $t$ test compared to $21 \%$ oxygen; $b$ indicates $p<0.001$ by $t$ test compared to $4 \%$ oxygen. $n=$ minimum of four per condition 
These data indicate that the formation of neurites under hypoxia from PC12 cells requires VEGF signaling.

\section{PC12 Metabolism is Altered by Hypoxia and VEGF}

Because neurite formation involves changes in cellular metabolism, we sought to ascertain whether hypoxia, hypoxia mimetics, or VEGF signaling altered PC12 metabolism. PC12 cells cultured under reduced oxygen tension of $4 \%$ or $1 \%$ exhibited a trend for greater reduction of alamarBlue, demonstrating enhanced metabolic activity and viability, compared to cells cultured at $21 \%$ oxygen (Fig. 4a). Both the hypoxia mimetic $\mathrm{CoCl}_{2}$ and recombinant VEGF enhanced PC12 metabolic activity in cells cultured at $21 \%$ oxygen tension, whereas the HIF antagonist YC-1 and VEGF-inhibiting antibody attenuated hypoxia-driven increases in metabolism (Fig. 4b).

\section{Discussion}

In this study, we demonstrate that neurite formation from a model neuronal cell line is influenced by the local oxygen microenvironment upon activation of HIF- $1 \alpha$ and autocrine VEGF action. Specifically, PC12 cells cultured in physiologically relevant oxygen tensions exhibited increased neurite outgrowth, total neurite length, and metabolic activity compared to cells cultured in ambient air. PC12 cells demonstrated significant increases in both the frequency of neurite extension and the maturity of the neural network when cultured in 4\% oxygen, correlating with known conditions for healthy mammalian neural tissue (Chen et al. 2007). This effect was mimicked at $21 \%$ oxygen tension through HIF- $\alpha$ stabilization with a hypoxia mimetic and exogenous VEGF, and hypoxia-driven neurite formation was blunted through the use of small molecule antagonists and neutralizing antibodies. These are the first data to indicate neurite formation under hypoxia involves autocrine action of VEGF.

In the present study, we utilized a common hypoxia mimetic $\left(\mathrm{CoCl}_{2}\right)$ and an inhibitor of HIF-1 $\alpha$ dimerization (YC-1) in order to further explore the link between oxygen responsiveness and neuronal differentiation. PC12 cells cultured at $21 \%$ oxygen exposed to $\mathrm{CoCl}_{2}$ extended neurites to a similar degree as cells maintained at $4 \%$ oxygen, suggesting that HIF- $\alpha$ stabilization is involved in this process (Fig. 2b). This finding is in agreement with those of Pacary et al. (2006, 2007, 2008), who reported neurite outgrowth and induction of the microtubuleassociated protein tau in $100 \mu \mathrm{M} \mathrm{CoCl}{ }_{2}$-treated cultures. Kotake-Nara et al. have also demonstrated neurite outgrowth in PC12 cells in response to $\mathrm{CoCl}_{2}$ (Kotake-Nara et al. 2005; Kotake-Nara and Saida 2006, 2007); in contrast to our work, their experimental conditions led to the formation of reactive oxygen species owing to higher concentrations of $\mathrm{CoCl}_{2}(200-500 \mu \mathrm{M})$.

To contrast the effects of $\mathrm{CoCl}_{2}$, we supplemented the culture medium with YC-1, a small molecule inhibitor of post-translational accumulation of HIF- $1 \alpha$ necessary for dimerization of HIF-1, thereby abolishing the transcriptional response mechanism to hypoxia (Kim et al. 2006). We hypothesized that if HIF isoforms were responsible for neurite outgrowth at lower oxygen tensions, suppression of HIF-1 and the associated hypoxic response genes by YC-1 would yield similar neurite production as cells cultured at $21 \%$ oxygen. We observed statistically similar fractions of PC12s extending neurites (Fig. 2b) and total neurite length (data not shown) in the presence of YC-1 for cells cultured at $4 \%$ oxygen compared to cells maintained in ambient air.

Recent data have demonstrated that low oxygen tension favors neurogenesis. Neural progenitor cells in reduced oxygen $(2 \%)$ or transient anoxia exhibit increased prolifer-

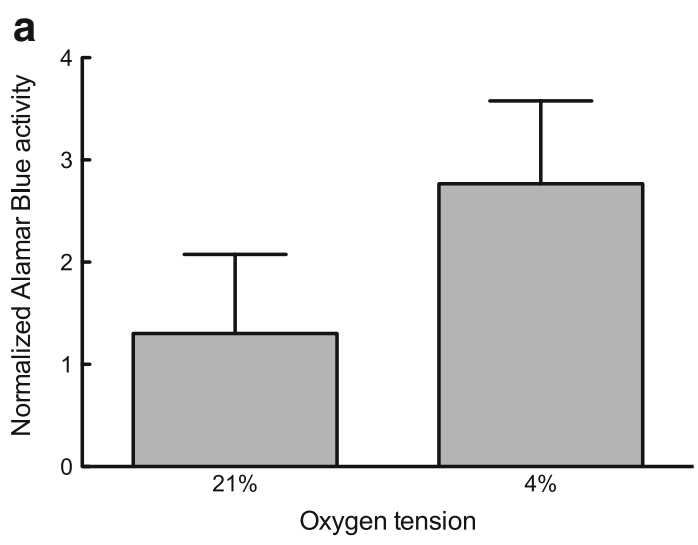

Figure 4 PC12 metabolic activity is altered by hypoxia and VEGF signaling. a PC12 cells reveal increased metabolic activity when cultured under $4 \%$ oxygen tension. b The hypoxia mimetic $100 \mu \mathrm{M}$

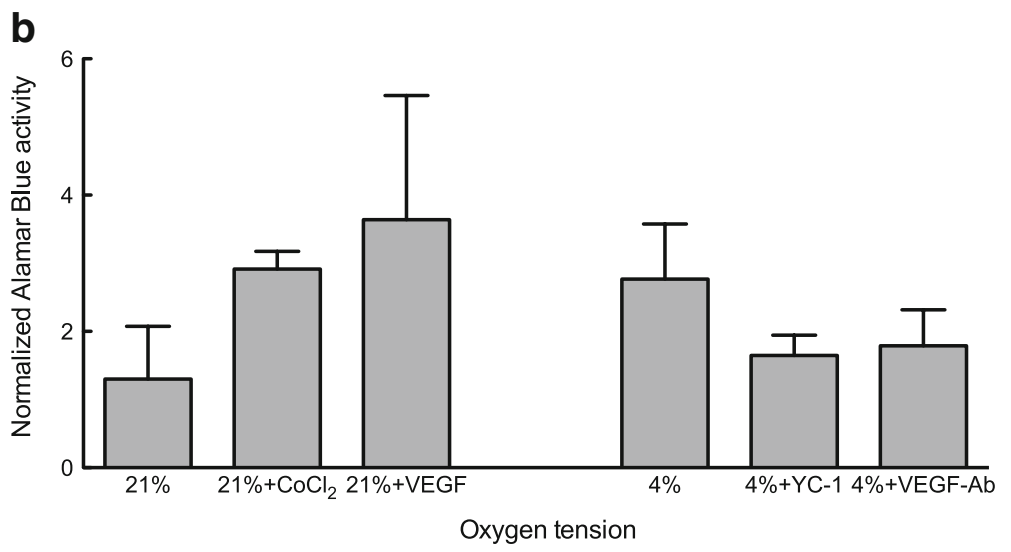

$\mathrm{CoCl}_{2}$ or $50 \mathrm{ng} / \mathrm{mL}$ VEGF increase metabolic activity, whereas the hypoxia antagonist $\mathrm{YC}-1$ or VEGF-inhibiting antibody attenuates hypoxic increases in metabolic activity. $n=3$ per condition 
ation and survival in vitro (Burgers et al. 2008; Horie et al. 2008), while transient cerebral ischemia in the mouse resulted in enhanced neurogenesis in the subventricular zone (Ong et al. 2005; Kadam et al. 2008). The survival and increased activity of neural cells at reduced oxygen may well be linked to the localized presentation of VEGF, a downstream product of HIF- $\alpha$ stabilization following cellular exposure to hypoxic conditions. Previous work demonstrated that the addition of VEGF to a hypoxic culture environment exerted a neuroprotective effect on a hippocampal neuronal cell line (Sheng et al. 2000). Beyond merely promoting survival, our findings indicate that endogenous VEGF may also promote neural differentiation at oxygen tensions approximating physiological conditions. PC12 cells cultured in the presence of exogenous VEGF exhibited increased neurite extension compared to cells cultured in ambient air (Fig. 3b). Furthermore, the neutralization of VEGF activity translated to reductions in neurite extension statistically similar to PC12s cultured at $21 \%$ oxygen and significantly lower than PC12s cultured in reduced oxygen conditions.

These data demonstrate that the oxygen microenvironment has a profound impact on the differentiation of neuronal cell populations, and the results presented herein are critically important when considering strategies for promoting neural repair. Currently, clinical approaches to neural repair include surgical methods to eliminate the existing gap between damaged or severed nerves, as well as morphogen presentation to stimulate the migration or differentiation of existing neural populations. Some of the most common growth factors used to promote neural tissue regeneration are from the neurotrophin family including nerve growth factor (NGF), neurotrophin-3 (NT-3), neurotrophin-4/5, and brain-derived neurotrophic factor (BDNF) (Tarasenko et al. 2004). While localized neurotrophin delivery can promote neurite extension (Sayer et al. 2002; Lee et al. 2003), this strategy often requires high doses that can induce aberrant axonal extension, resulting in allodynia without markedly improved motor function. In light of the close interaction between the neural structure and vascular system, additional study is merited to understand the signaling events and feedback resulting from paracrineacting molecules secreted by neural and endothelial cells within the nervous system.

Neural cells are exposed to various oxygen conditions during development, tissue repair, or transplantation, all of which are significantly lower than atmospheric levels. It is therefore vital to study cellular responses to these conditions when pursuing new strategies for tissue repair or modeling tissue formation in vitro. At this time, the precise mechanism by which HIF- $\alpha$ triggers neurite extension is unclear. Previous studies have confirmed a link between hypoxia and the formation of focal adhesions (Seko et al. 1999), but we were unable to detect the simultaneous upregulation of HIF- $1 \alpha$ and phosphorylated focal adhesion kinase (pFAK) by Western blotting in cells exposed to reduced oxygen, nor did we observe significant changes in neurofilament L expression (data not shown). In summary, this data confirms the importance of both HIF-1 $\alpha$ and VEGF for neurite extension in the presence of physiologically relevant oxygen tensions, and these findings may serve to identify novel targets and approaches to enhance neural differentiation.

Acknowledgments This work was supported in part by the T32 PreDoctoral Clinical Research Training Program (UC Davis School of Medicine and Clinical and Translational Science Center) and the Achievement Rewards for College Scientists (ARCS) Foundation (WKC).

Open Access This article is distributed under the terms of the Creative Commons Attribution Noncommercial License which permits any noncommercial use, distribution, and reproduction in any medium, provided the original author(s) and source are credited.

\section{References}

Burgers HF, Schelshorn DW, Wagner W, Kuschinsky W, Maurer MH (2008) Acute anoxia stimulates proliferation in adult neural stem cells from the rat brain. Exp Brain Res 188:33-43

Chen PS, Zhai WR, Zhou XM, Zhang JS, Zhang YE, Ling YQ, Gu YH (2001) Effects of hypoxia, hyperoxia on the regulation of expression and activity of matrix metalloproteinase- 2 in hepatic stellate cells. World J Gastroenterol 7:647-651

Chen HL, Pistollato F, Hoeppner DJ, Ni HT, McKay RD, Panchision DM (2007) Oxygen tension regulates survival and fate of mouse central nervous system precursors at multiple levels. Stem Cells 25:2291-2301

Hamid R, Rotshteyn Y, Rabadi L, Parikh R, Bullock P (2004) Comparison of alamar blue and MTT assays for high through-put screening. Toxicol In Vitro 18:703-710

Horie N, So K, Moriya T, Kitagawa N, Tsutsumi K, Nagata I, Shinohara K (2008) Effects of oxygen concentration on the proliferation and differentiation of mouse neural stem cells in vitro. Cell Mol Neurobiol 28:833-845

Hurlbert RJ (2006) Strategies of medical intervention in the management of acute spinal cord injury. Spine 31:S16-S21, discussion $\mathrm{S} 36$

Kadam SD, Mulholland JD, McDonald JW, Comi AM (2008) Neurogenesis and neuronal commitment following ischemia in a new mouse model for neonatal stroke. Brain Res 1208:3545

Kim HL, Yeo EJ, Chun YS, Park JW (2006) A domain responsible for HIF-1alpha degradation by YC-1, a novel anticancer agent. Int J Oncol 29:255-260

Kotake-Nara E, Saida K (2006) Endothelin-2/vasoactive intestinal contractor: regulation of expression via reactive oxygen species induced by $\mathrm{CoCl} 2$, and Biological activities including neurite outgrowth in PC12 cells. ScientificWorldJournal 6:176-186

Kotake-Nara E, Saida K (2007) Characterization of CoCl2-induced reactive oxygen species (ROS): Inductions of neurite outgrowth and endothelin-2/vasoactive intestinal contractor in PC12 cells by 
$\mathrm{CoCl} 2$ are $\mathrm{ROS}$ dependent, but those by $\mathrm{MnCl} 2$ are not. Neurosci Lett 422:223-227

Kotake-Nara E, Takizawa S, Quan J, Wang H, Saida K (2005) Cobalt chloride induces neurite outgrowth in rat pheochromocytoma PC12 cells through regulation of endothelin-2/vasoactive intestinal contractor. J Neurosci Res 81:563-571

Leach JB, Brown XQ, Jacot JG, Dimilla PA, Wong JY (2007) Neurite outgrowth and branching of PC12 cells on very soft substrates sharply decreases below a threshold of substrate rigidity. J Neural Eng 4:26-34

Lee AC, Yu VM, Lowe JB 3rd, Brenner MJ, Hunter DA, Mackinnon SE, Sakiyama-Elbert SE (2003) Controlled release of nerve growth factor enhances sciatic nerve regeneration. Exp Neurol 184:295-303

Livak KJ, Schmittgen TD (2001) Analysis of relative gene expression data using real-time quantitative PCR and the 2(-Delta Delta C (T)) Method. Methods 25:402-408

Meijering E, Jacob M, Sarria JC, Steiner P, Hirling H, Unser M (2004) Design and validation of a tool for neurite tracing and analysis in fluorescence microscopy images. Cytometry A 58: $167-176$

Milosevic J, Schwarz SC, Krohn K, Poppe M, Storch A, Schwarz J (2005) Low atmospheric oxygen avoids maturation, senescence and cell death of murine mesencephalic neural precursors. J Neurochem 92:718-729

Ong J, Plane JM, Parent JM, Silverstein FS (2005) Hypoxic-ischemic injury stimulates subventricular zone proliferation and neurogenesis in the neonatal rat. Pediatr Res 58:600-606

Pacary E, Legros H, Valable S, Duchatelle P, Lecocq M, Petit E, Nicole O, Bernaudin M (2006) Synergistic effects of $\mathrm{CoCl}(2)$ and ROCK inhibition on mesenchymal stem cell differentiation into neuron-like cells. J Cell Sci 119:2667-2678

Pacary E, Tixier E, Coulet F, Roussel S, Petit E, Bernaudin M (2007) Crosstalk between HIF-1 and ROCK pathways in neuronal differentiation of mesenchymal stem cells, neurospheres and in PC12 neurite outgrowth. Mol Cell Neurosci 35: 409-423

Pacary E, Petit E, Bernaudin M (2008) Concomitant inhibition of prolyl hydroxylases and ROCK initiates differentiation of mesenchymal stem cells and PC12 towards the neuronal lineage. Biochem Biophys Res Commun 377:400-406
Potier E, Ferreira E, Dennler S, Mauviel A, Oudina K, LogeartAvramoglou D, Petite H (2008) Desferrioxamine-driven upregulation of angiogenic factor expression by human bone marrow stromal cells. J Tissue Eng Regen Med 2:272-278

Safford KM, Rice HE (2005) Stem cell therapy for neurologic disorders: therapeutic potential of adipose-derived stem cells. Curr Drug Targets 6:57-62

Sayer FT, Oudega M, Hagg T (2002) Neurotrophins reduce degeneration of injured ascending sensory and corticospinal motor axons in adult rat spinal cord. Exp Neurol 175:282-296

Schmidt CE, Leach JB (2003) Neural tissue engineering: strategies for repair and regeneration. Annu Rev Biomed Eng 5:293-347

Seko Y, Takahashi N, Sabe H, Tobe K, Kadowaki T, Nagai R (1999) Hypoxia induces activation and subcellular translocation of focal adhesion kinase (p125(FAK)) in cultured rat cardiac myocytes. Biochem Biophys Res Commun 262:290-296

Semenza GL (2007) Life with oxygen. Science 318:62-64

G.L. Semenza, Hypoxia-inducible factor 1 (HIF-1) pathway. Sci STKE 2007 (2007a) cm8

Sheffield JB, Graff D, Li HP (1987) A solid-phase method for the quantitation of protein in the presence of sodium dodecyl sulfate and other interfering substances. Anal Biochem 166:49-54

Sheng H, Shao J, Dixon DA, Williams CS, Prescott SM, DuBois RN, Beauchamp RD (2000) Transforming growth factor-beta 1 enhances Ha-ras-induced expression of cyclooxygenase-2 in intestinal epithelial cells via stabilization of mRNA. J Biol Chem 275:6628-6635

Sun HL, Liu YN, Huang YT, Pan SL, Huang DY, Guh JH, Lee FY, Kuo SC, Teng CM (2007) YC-1 inhibits HIF-1 expression in prostate cancer cells: contribution of Akt/NF-kappaB signaling to HIF1alpha accumulation during hypoxia. Oncogene 26:3941-3951

Tarasenko YI, Yu Y, Jordan PM, Bottenstein J, Wu P (2004) Effect of growth factors on proliferation and phenotypic differentiation of human fetal neural stem cells. J Neurosci Res 78:625-636

Yeh WL, Lu DY, Lin CJ, Liou HC, Fu WM (2007) Inhibition of hypoxia-induced increase of blood-brain barrier permeability by YC-1 through the antagonism of HIF-1alpha accumulation and VEGF expression. Mol Pharmacol 72:440-449

Zhu LL, Wu LY, Yew DT, Fan M (2005) Effects of hypoxia on the proliferation and differentiation of NSCs. Mol Neurobiol 31:231242 